\title{
Sobre la diversidad del olivar andaluz: del territorio al paisaje (El caso de la provincia de Jaén)
}

\section{The diversity of the Andalusian olive grove:} from territory to landscape (The case study of the province of Jaén) La diversité de l'oliveraie andalouse:
de territoire au paysage
(Étude de cas dans la province de Jaén)

José Domingo Sánchez Martínez ${ }^{1}$, Antonio Garrido Almonacid ${ }^{2}$

\begin{abstract}
RESUMEN
El olivar es el cultivo más común y la base económica de gran parte de los municipios rurales de Andalucía, a menudo alcanzando la condición de monocultivo, sumando en conjunto una superficie de más de un millón y medio de hectáreas. Para contribuir al mantenimiento y proyección de los territorios donde está presente, la conservación y valorización del paisaje y la cultura del olivar se contempla ahora como un activo de desarrollo sostenible y competitividad regional, lo que ha llevado incluso a plantear su reconocimiento patrimonial al más alto nivel internacional. Más allá de la consideración del olivar como un todo, en nuestro trabajo se pretende demostrar la inmensa diversidad interna que contiene, y cómo esta se plasma en términos paisajísticos. Para ello hemos creado una base de datos espacial en la que se integran variables agrícolas,
\end{abstract}

\footnotetext{
1 Universidad de Jaén. jdsanche@ujaen.es ORCID iD: http://orcid.org/0000-0002-44284186

2 Universidad de Jaén. agarrido@ujaen.es ORCID iD: http://orcid.org/0000-0002-6479_ 2698
} 
cronológicas y espaciales. Como resultado final se presentan cuatro grandes categorías de paisajes olivareros: marginales, en áreas protegidas, tradicionales y productivistas.

Palabras Clave: aceite de oliva; desarrollo rural; paisajes rurales; patrimonio agrario; sistemas de información geográfica.

\begin{abstract}
Olive grove is the most common crop and the economic basis of much of the rural municipalities of Andalusia, often reaching the condition of monoculture. To contribute to the maintenance and development of these territories, the conservation and enhancement of the landscape and culture of the olive grove is currently seen as an asset for sustainable development and regional competitiveness. The objective of our work is to show the vast internal diversity it contains, and how this is reflected in landscape terms. So, we've created a spatial database in which agricultural, chronological and spatial variables are integrated. As a final result four broad categories of olive landscapes are presented: marginal, in protected areas, traditional and productivists.
\end{abstract}

KEY wORDS: olive oil; rural development; rural landscapes; agrarian heritage; geographic information systems.

RÉSUMÉ

Loliveraie est la culture la plus commune et la base économique de la plupart des municipalités rurales de l'Andalousie, atteignant souvent la condition de monocultures. Pour contribuer au maintien et au développement de ces territoires, la conservation et l'amélioration du paysage et de la culture de l'oliveraie est désormais considérée comme un atout pour le développement durable et la compétitivité régionale. Lobjectif de notre travail est de montrer la grande diversité interne qu'il contient, et comment cela se traduit en termes de paysage. Nous avons donc créé une base de données spatiale dans laquelle les variables agricoles, chronologiques et spatiales sont intégrées. Comme résultat final quatre grandes catégories de paysages d'oliviers sont présentés: marginal, dans les zones protégées, traditionnel et productivistes.

Mots-Clés: huile d'olive; développement rural; paysages ruraux; patrimoine agraire; systèmes d'information géographique.

Cómo citar este artículo/Citation: Sánchez Martínez, José Domingo, Garrido Almonacid, Antonio (2017): "Sobre la diversidad del olivar andaluz: del territorio al paisaje (El caso de la provincia de Jaén)", Estudios Geográficos, LXXVIII/283, pp. 523-551 


\section{INTRODUCCIÓN}

En un intento por contribuir al mantenimiento y proyección de las zonas rurales, determinados cultivos y sus paisajes agrarios comienzan a valorarse desde el punto de vista patrimonial y los territorios donde se implantan a configurarse como nuevos destinos turísticos. Un caso paradigmático de cuanto decimos es lo que ocurre con el viñedo y el vino (Cañizares y Ruiz, 2014; Ruiz y Lasanta, 2014; Peris-Ortiz, M. et al., 2016), que es de largo la actividad agraria que más atención ha recibido por organismos internacionales como la UNESCO a la hora de reconocer los valores culturales y promocionar su declaración patrimonial (Castillo y Martínez, 2014). Se vinculan estas actividades, en todo caso, con un amplio conjunto de estrategias surgidas para superar el modelo agrario tradicional, que genéricamente podemos identificar con la teoría del desarrollo rural o tendencia hacia la multifuncionalidad de las áreas rurales y el postproductivismo agrario (Evans y Bowler, 1998; Van der Ploeg y Roep, 2003; Armesto, 2005, OCDE, 2006). Esto es lo que está ocurriendo, desde luego, en los territorios olivareros andaluces, sobre los cuales las autoridades políticas han tomado una serie de decisiones que dirigen hacia esa finalidad, entre las que destacan la aprobación de la Ley 5/2011, de 6 de octubre, del olivar de Andalucía ${ }^{3}$, la publicación del Plan Director del Olivar Andaluz (Consejería de Agricultura, Pesca y Desarrollo Rural, 2015), que es el instrumento previsto para su desarrollo, y el comienzo (a partir de 2014) de los trabajos conducentes a la elaboración del expediente que permita aspirar a la inclusión del paisaje cultural del olivar en la Lista del Patrimonio Mundial, cuyo liderazgo ha sido asumido por la Diputación Provincial de Jaén ${ }^{4}$. Iniciativas a las que cabe sumar la de colectivos privados como la «Asociación para la promoción de las aceitunas sevillanas de las variedades Manzanilla y Gordal», que pretende solicitar a la UNESCO que la técnica de recolección manual de tales aceitunas (el verdeo) sea reconocido como Patrimonio Cultural Inmaterial de la Humanidad 5 .

Más allá de estas consideraciones, el olivar andaluz tiene una trascendencia territorial innegable. Como quedó recogido en la exposición de motivos de la Ley del Olivar: «representa la tercera parte del olivar europeo; produce el $40 \%$ del aceite y el $20 \%$ de la aceituna de mesa en el mundo; es lugar de asiento de más de ochocientas

3 http://www.juntadeandalucia.es/boja/2011/205/1 (acceso 30/11/2015).

4 http://www.europapress.es/andalucia/cultura-00621/noticia-cultura-empieza-optimismoelaboracion-expediente-olivar-sea-paisaje-patrimonio-mundial-20140924141905.html (acceso de 30/11/2015).

5 http://www.olimerca.com/noticiadet/el-verdeo-quiere-llegar-a-ser-patrimonio-cultura-dela-humanidad/d6ced98a495891f2b8735196df0dfc39 (acceso de 11/03/2016). 
almazaras, más de doscientas entamadoras, unas treinta y cinco extractoras de orujo y casi seiscientas envasadoras de aceite; constituye la principal actividad de más de trescientos pueblos andaluces en los que viven más de doscientas cincuenta mil familias de olivareros, y proporciona más de veintidós millones de jornales al año [...] La producción de aceite de oliva en la Comunidad Autónoma fluctúa en torno al millón de toneladas, y la de aceituna de mesa alrededor de las cuatrocientas mil toneladas. El valor de la producción de aceite de oliva y de la aceituna de mesa percibido por los olivicultores supone aproximadamente el 24\% de la producción en valor de la rama agraria andaluza» (pág. 6).

El trabajo que presentamos ahora enlaza con investigaciones previas que nos han permitido reconocer momentos y patrones espaciales de la formación del monocultivo olivarero a través de fuentes escritas y cartográficas (Sánchez y Parras, 2014; Paniza, García y Sánchez, 2015), y que ahora dan paso a un intento de mostrar la diversidad territorial y sus correlatos paisajísticos de los olivares andaluces, que se extienden por zonas de fisiografía y estructura económica contrastada pues no hay que olvidar que ocupa 1,5 millones de hectáreas, más del doble de las existentes a comienzos del siglo XX. De ellas, el $20 \%$ han sido plantadas desde el momento en el que España se incorporó al Mercado Común Europeo en 1985 (Sánchez, Rodríguez y Gallego, 2015). No obstante, por razones operativas y que tienen que ver con un conocimiento más directo del medio, el trabajo toma como área de estudio la provincia de Jaén, el paradigma del monocultivo olivarero pero, al mismo tiempo, un buen ejemplo de la enorme diversidad interna que este puede llegar a tener desde una perspectiva agrícola, económica y paisajística (Sánchez y Paniza, 2015). Este ejercicio tiene como objetivo, no obstante, testar la eficacia de la metodología empleada para su extensión posterior al conjunto del olivar andaluz.

Para atender a este objetivo general, comenzaremos explicando algunas claves de la dimensión y características del olivar; a continuación se discutirá sobre las aproximaciones que se han hecho en España al estudio de los paisajes agrarios; en tercer lugar se expondrá la metodología seguida para aproximarse a la diversidad económico-territorial de los olivares existentes; en un último apartado se apunta una primera aproximación a los paisajes que pueden reconocerse a partir de tal diversidad.

\section{REPASO DE LA TEORÍA Y LA LITERATURA}

El cultivo olivarero alcanza una extraordinaria dimensión superficial en el sur de España. Se extiende por el $43 \%$ de las tierras labradas, por 
suelos de diferente capacidad agraria (figura 1), lo que da a entender su trascendencia territorial y justifica plenamente que se haya calificado como el «principal paisaje de la Comunidad Autónoma de Andalucía» (Guzmán y Zoido, 2013). En la caracterización de este monocultivo agrario ha de prestarse atención especial al efecto que han tenido las políticas agrarias recientes y, en particular, la profunda incidencia de la PAC, especialmente en su período de orientación productivista-proteccionista, en gran medida responsable del notable incremento de las producciones que se han observado en las tres últimas décadas. Este proceso no ha estado exento de la generación de externalidades negativas (Beaufoy, 2001), ni ha supuesto una homogeneización total del espacio cultivado, si bien es cierto que la intensificación ha sido generalizada. Como resultado, conviven en la actualidad olivares de muy diferente condición (Sánchez, Rodríguez y Gallego, 2015). Dado el distinto desempeño que cada uno de ellos tiene

\section{FIGURA 1}

\section{DISTRIBUCIÓN DEL OLIVAR ANDALUZ EN RELACIÓN A LA CALIDAD DEL SUELO OCUPADO (2007)}

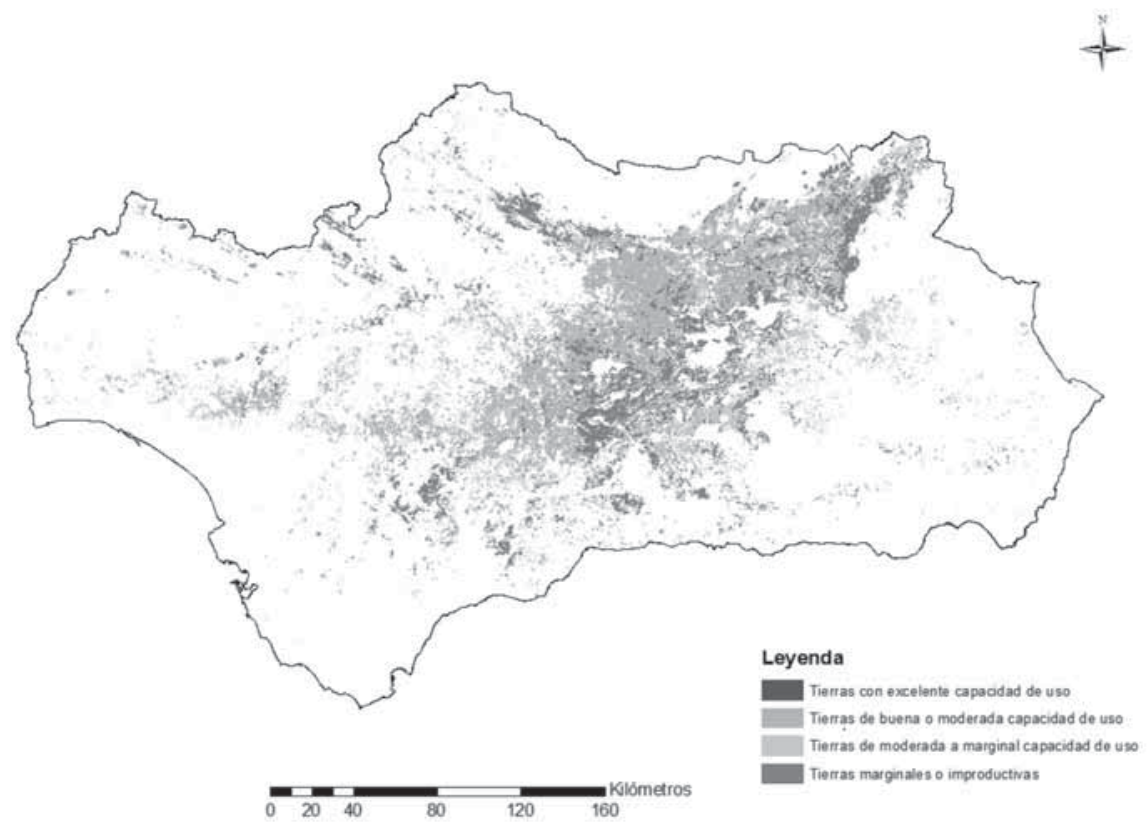

Fuente: Red de Información Ambiental de Andalucía. 
en términos de sostenibilidad es por lo que, durante el período anterior a la última reforma de la PAC aprobada, se propuso la discriminación y limitación temporal de las ayudas en función de tal variopinta capacidad (Gómez-Limón y Arriaza, 2011), una consideración que sin embargo no se corresponde con lo finalmente establecido, que prácticamente puede considerarse como una subvención con «tarifa plana», concediendo cantidades similares a las percibidas con anterioridad a través del régimen de pago único (Sánchez, Rodríguez y Gallego, 2015).

Precisamente, la manera más habitual de clasificar la diversidad existente es la identificación de varias clases productivas en relación a los rendimientos medios de la planta (Junta de Andalucía, 2008; AEMO, 2010; Consejo Económico y Social de la Provincia de Jaén, 2011; Colombo et al. 2015). Así, poco tienen que ver desde esta perspectiva los olivares de montaña, que ocupan suelos marginales de clara vocación forestal, con las modernas plantaciones en espaldera. Si en el primer caso la media productiva puede estar en torno a los $500 \mathrm{~kg} / \mathrm{ha} /$ año de aceituna, en el segundo esta cantidad se puede multiplicar por 30 o más veces. Recientemente, la administración andaluza ha establecido dos grandes categorías tomando como referencia el umbral de $4.000 \mathrm{~kg} / \mathrm{ha} / \mathrm{año}$, resultando que el $77,11 \%$ de la superficie está ocupada por olivares tradicionales, esto es, sin capacidad para superar esta referencia, siendo el resto modernos olivares de carácter intensivo y superintensivo (Consejería de Agricultura, Pesca y Alimentación, 2015).

Estas aproximaciones a la diversidad olivarera se han realizado (con la excepción de la aportada por Colombo et al., 2015) sin una representación cartográfica precisa ni la pretensión de establecer una clasificación de orden paisajística. De hecho, la mera aparición de cartografía temática específica de las masas olivareras se limita al Inventario Agronómico del Olivar, realizado por el Ministerio de Agricultura en 1975 (véase figura 2); si bien es posible reconstruir la expansión y localización de la planta a partir de diferentes fuentes cartográficas, fotográficas y satelitales al menos desde finales del siglo XIX (Moya, Cuesta y Sánchez, 2015; Paniza, García y Sánchez, 2015).

El interés por delimitar y caracterizar los paisajes agrarios y, dentro de ellos, los que están dominados por la presencia del olivar se puede rastrear, no obstante, en la obra de investigadores que han trabajado en este tema durante las dos últimas décadas. La primera gran aportación en ese sentido, si bien en términos muy generales, (Mata Olmo, 1997 y 2001), aclara la necesidad de establecer los paisajes agrarios a pequeña escala considerando factores fisiográficos (clima, relieve), fundiarios y los usos del suelo dominantes. Así, llega a reconocer seis grandes agrosistemas en los que diferencia una veintena 


\section{FIGURA 2}

MASAS DE OLIVAR EN LA COMARCA OLIVARERA JAÉN-MARTOS, 1975

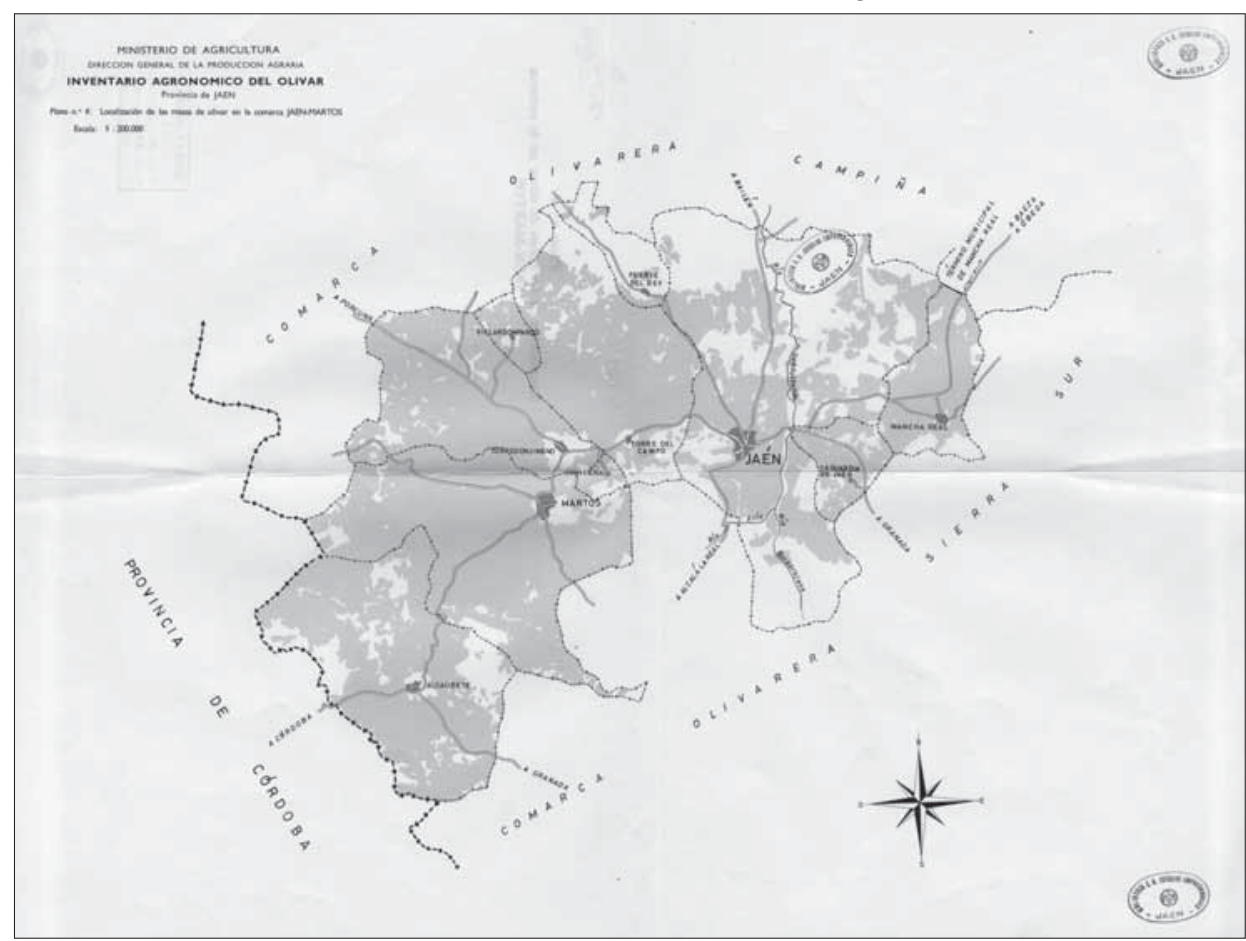

Fuente: Ministerio de Agricultura (1975).

de paisajes característicos ${ }^{6}$. Aproximaciones aún más globales, pero también muy válidas para acercarnos al fin que estamos persiguiendo, como después se comprobará, pueden encontrarse en el Atlas de los paisajes de España (Mata y Sanz, 2003) y el Mapa de los Paisajes de Andalucía (Junta de Andalucía, 2005).

Un paso más reciente y centrado exclusivamente en los paisajes agrarios (Molinero, Tort y Ojeda, 2010) fija su atención en delimitarlos a partir de una aproximación escalar en la que diferentes factores y elementos cobran protagonismo en varios momentos. Como resultado, se establecen 3 dominios paisajísticos (atlánticos, mediterráneos y canarios), diez categorías paisajísticas

6 A modo de ejemplo, entre ellos se reconoce el agrosistema de los leñosos mediterráneos, en los que se incluye el olivar o, como el propio autor explica, "los olivares españoles, pues la diversidad de variedades, técnicas y sistemas de explotación es considerable, ocupando alrededor de dos millones de hectáreas" (Mata Olmo, 2001, 307) 
(considerando el uso ganadero, agrícola o forestal dominante) y veintiséis clases de paisajes agrarios ${ }^{7}$. Además, en una segunda parte de este trabajo se estudian ejemplos singulares de paisajes que se definen como arquetípicos, como es el caso de la Loma de Úbeda como representación de las campiñas olivareras andaluzas (Sánchez y Gallego, 2010). Más recientemente, la publicación de sendos tomos del Atlas de los paisajes agrios de España (Molinero, 2013 y 2014) profundiza y matiza la taxonomía antes citada, lo que ha dado lugar a una nueva y abundante inclusión de clases de paisaje que viene a complementar la veintena que aparecieron en la obra de 2010, por lo que permiten en conjunto contar con una representación de los paisajes más sobresalientes del territorio pero en absoluto de la totalidad, pues no se ha acabado de presentar una delimitación completa y sistemática de tales unidades.

Hay que recordar igualmente que ya en la década pasada (Guzmán Álvarez, 2004 y 2007) se estableció una clasificación paisajística-territorial de los olivares en Andalucía, concretada en 11 tipos de paisaje, que son nombrados de acuerdo a las características fisiográficas de su localización, sobre todo en relación con la topografía y la litología. Estos tipos se distribuyen en un total de 76 unidades territoriales delimitadas según rasgos del medio físico y fisionomía del paisaje ${ }^{8}$, cada una de las cuales se identifica con un tipo de paisaje olivarero característico. Este es el único caso de cartografía temática precisa del olivar andaluz hasta el momento, con el añadido que este se distribuye entre cinco clases según su perfil económico-ecológico. De acuerdo a este concepto se encuentran desde olivares sin limitaciones hasta aquellos que se califican como marginales o muy marginales (clases 4 y 5 ). Según los cálculos presentados en este trabajo, en la provincia de Jaén se reconocieron un total de 66.472 ha de olivares marginales, mayoritariamente localizados en zonas de montaña (Sierra Sur de Jaén, Sierra Mágina y Sierra de Segura sobre todo). De estas, se estimó que, si se producía el abandono del cultivo, casi el $70 \%$ del suelo sería recolonizado por vegetación leñosa. La utilidad en términos de ordenación territorial de este estudio resulta, por tanto, manifiesta.

Del repaso bibliográfico que acabamos de hacer pueden resaltarse varias ideas: de una parte el progresivo interés por inventariar y caracterizar los paisajes agrarios españoles, y no solo por razones de índole académica sino también por

7 En este trabajo, los olivares son una clase integrada en la categoría de los paisajes de los cultivos leñosos mediterráneos, que forman parte a su vez del domino de los paisajes agrarios mediterráneos y canarios.

8 Así, se diferencian los olivares de campiña (v.g. Campiña Norte de Jaén), de los que ocupan suelos aluviales (Valle del Guadalquivir de Jaén) o las laderas montañosas (Sierra Morena, Sierra Sur, Sierra Magina, etc.). 
la demanda social, cada vez más preocupada y sensible con la suerte y dinámica de los entornos en los que se desenvuelve, así como por la utilidad que pueden tener a los efectos de ordenación territorial (Junta de Andalucía 2011). Por otra parte, la variedad de aproximaciones metodológicas, si bien es habitual el manejo de tres escalas de delimitación (aunque no se emplea una terminología común para nombrarlas) y el predominio de los métodos de superposición cartográfica para lograr síntesis representativas de los paisajes reconocidos. De la misma forma, hay que destacar el estudio de los usos del suelo como elemento identificador más claro de la cartografía del paisaje agrario, «por cuanto al extenderse por la mayor parte del territorio proporcionan su trama y formas, su textura y sus colores» (Molinero, Alario y Baraja, 2015, 1123). Lo que no implica, en cualquier caso, que el paisaje se limite al uso del suelo pues este se acompaña de otros elementos igualmente preciosos, algunos visibles y otros más crípticos, como el poblamiento, la trama caminera o el parcelario, y que en el caso concreto del olivar actual son también las balsas de riego, las casas de labor o la infraestructura industrial asociada a la transformación de su fruto.

Dentro de un contexto de búsqueda de la multifuncionalidad en el mundo rural, en el caso andaluz pensamos que uno de los detonantes de la atención sobre el paisaje olivarero y el reconocimiento de sus valores patrimoniales es la inauguración de una nueva etapa en la que los productores están considerando como parte de su estrategia empresarial la obtención de aceites de la máxima calidad (Rodríguez, Sánchez y Gallego, 2015). Si bien la opción mayoritaria todavía sigue siendo buscar la competitividad mediante la reducción de costes antes que por diferenciación, parece obvio que la aparición de centenares de marcas embotelladas y etiquetadas al gusto de los mercados más refinados y exigentes ha despertado el interés por conocer la riqueza y complejidad de los procesos, territorios y paisajes que están detrás de su producción. La obtención de premios nacionales e internacionales o la popularización de las catas de aceite para apreciar matices y calidades es una prueba de este cambio de orientación y de superación de una imagen del sector aceitero asociada al atraso (Medina Rosillo, 2015).

El propósito de «conservar y valorizar el paisaje y el patrimonio histórico y cultural del olivar y sus productos» es una finalidad asumida en la Ley del Olivar de Andalucía y el instrumento para alcanzar tales objetivos es el Plan Director del Olivar de Andalucía (2014), donde se recogen las posibilidades de actuación para mejorar el desarrollo socioeconómico de la región a través de la intervención en los territorios olivareros, acogiéndose para ello a los principios y financiación del Programa de Desarrollo Rural de Andalucía 2014-2020 (Junta de Andalucía, 2014), que se impregna del concepto de «especialización inteligente» (Foray, 2013). En este sentido, se busca una orientación hacia 
el conocimiento y la innovación, el uso eficiente y priorizado de los recursos para alcanzar un desarrollo sostenible y la elevación del nivel de empleo en aras a conseguir una mayor cohesión territorial y social. En definitiva, que el territorio se contemple no solo como soporte del proceso de producción, sino como recurso y factor clave para el desarrollo (Maya e Hidalgo, 2009).

\section{TABLA 1}

ESTRATEGIAS Y ACTUACIONES CONTEMPLADAS EN EL PDOA EN RELACIÓN AL PAISAJE

\begin{tabular}{|c|c|c|}
\hline Estrategia & Líneas estratégicas & Actuaciones \\
\hline \multirow[t]{4}{*}{$\begin{array}{l}\text { Mantenimiento o impulso } \\
\text { del patrimonio olivarero } \\
\text { de Andalucía }\end{array}$} & \multirow{4}{*}{$\begin{array}{l}\text { Conservar y poner en } \\
\text { valor el patrimonio } \\
\text { natural, arqueológico, } \\
\text { genético, etnológico, } \\
\text { gastronómico e industrial } \\
\text { del olivar andaluz }\end{array}$} & $\begin{array}{l}\text { Establecer medidas de protección del patrimonio } \\
\text { representado por olivos y olivares singulares o } \\
\text { excepcionales, así como para el patrimonio arqueológico, } \\
\text { industrial y etnológico asociado al cultivo }\end{array}$ \\
\hline & & $\begin{array}{l}\text { Impulsar la localización, señalización y puesta en valor de } \\
\text { paisajes olivareros de especial relevancia histórica, cultural, } \\
\text { turística o agronómica. }\end{array}$ \\
\hline & & $\begin{array}{l}\text { Considerar al olivar amparado bajos figuras de protección } \\
\text { como las DOP, así como el olivar ecológico y en } \\
\text { producción integrada, de Interés Patrimonial }\end{array}$ \\
\hline & & $\begin{array}{l}\text { Impulsar la puesta en valor de los paisajes olivareros de } \\
\text { especial relevancia ambiental situados dentro de la red } \\
\text { Natura } 2000\end{array}$ \\
\hline \multirow{2}{*}{$\begin{array}{l}\text { Medidas para favorecer } \\
\text { la biodiversidad, calidad } \\
\text { paisajística de los olivares } \\
\text { y su contribución a la } \\
\text { sostenibilidad ambiental y } \\
\text { la lucha contra el cambio } \\
\text { climático }\end{array}$} & \multirow[t]{2}{*}{$\begin{array}{l}\text { Promover la gestión } \\
\text { sostenible de los recursos: } \\
\text { agua, suelo, biodiversidad } \\
\text { y paisaje }\end{array}$} & $\begin{array}{l}\text { Fomentar métodos de producción compatibles con el } \\
\text { medio ambiente que aseguren la gestión sostenible de los } \\
\text { recursos }\end{array}$ \\
\hline & & $\begin{array}{l}\text { Potenciar la biodiversidad de los olivares favoreciendo } \\
\text { su capacidad de acogida para la fauna y la flora no } \\
\text { competidora con el cultivo }\end{array}$ \\
\hline
\end{tabular}

Fuente: Consejería de Agricultura, Pesca y Alimentación (2015).

En el Plan Director del Olivar el paisaje se considera como una externalidad positiva del cultivo ${ }^{9}$, que presentaría una triple vertiente: estética, ecológica y

9 Esa misma categoría se concede al mantenimiento de la biodiversidad, la mitigación del cambio climático, la fijación de población en el medio rural, la generación de compuestos bioactivos saludables, el patrimonio cultural o las propiedades saludables del aceite y las aceitunas. 
cultural. En consonancia con lo recogido en la Estrategia de Paisaje de Andalucía (Junta de Andalucía, 2011), el paisaje se toma igualmente como un activo de desarrollo sostenible y de competitividad regional, aprobándose varias estrategias, líneas y actuaciones (véase tabla 1). En el Plan mencionado apenas se avanzan criterios de delimitación y diferenciación de los paisajes olivareros. Desde luego, esta labor se nos antoja tan compleja como necesaria. Nuestro propósito es precisamente adelantar unos primeros pasos en ese sentido.

\section{Metodología de LA inVestigación}

Se ha creado una base de datos georreferenciada, al objeto de disponer de una herramienta que permita con facilidad combinar diferentes atributos que nos permitan reconocer la diversidad del olivar. Entre las múltiples posibilidades existentes, nos hemos decantado por el manejo de cuatro atributos fundamentales: pendiente, densidad de plantación, antigüedad del cultivo y localización geográfica. Obviamente, esto significa un deliberado ejercicio de simplificación que, no obstante, creemos que permite reconocer de manera satisfactoria las claves de la diferenciación económico-territorial de los olivares. Inicialmente se ha recurrido al manejo del Sistema de Información Geográfica de Parcelas Agrícolas (SIGPAC), creado para almacenar información relativa a aquellas que son susceptibles de acogerse a ayudas agrarias calculadas de acuerdo a la superficie cultivada. En la versión que nosotros hemos empleado ${ }^{10}$ (2008), la unidad espacial de referencia en formato vectorial es la parcela, de la que, además de su posición, hemos manejado información alfanumérica referida a los datos catastrales (polígono, parcela, recinto), municipio al que pertenece, número de olivos plantados, pendiente media y superficie (véase figura 3 ).

De este conjunto de datos se desestimaron los recintos considerados complementarios a las parcelas olivareras, es decir, los dedicados a caminos de acceso, lindes, eriales, etc. ${ }^{11}$, pues la ausencia de plantación hacía innecesario y complejo su uso ${ }^{12}$. Por otra parte, al objeto de agilizar la gestión espacial

10 Aunque es posible el empleo de versiones posteriores, la razón que nos lleva a emplear la de este año es la correspondencia con otras fuentes disponibles, en este caso la capa de usos del suelo.

11 Para la provincia de Jaén el total de recintos individualizados espacialmente es de 1.245.816, de los cuales el 56,84\% están ocupados de olivos.

12 Somos conscientes, no obstante, de que si bien en términos económicos esta información es poco relevante, no ocurre así desde el punto de vista paisajístico, por lo que, junto con la propia forma, entramado y tamaño de las parcelas, resultará de gran utilidad en fases posteriores de la investigación que aquí se está planteando. 
FIGURA 3

BASE DE DATOS ESPACIAL DE REFERENCIA: INFORMACIÓN DISPONIBLE DE CADA UNA DE LAS PARCELAS

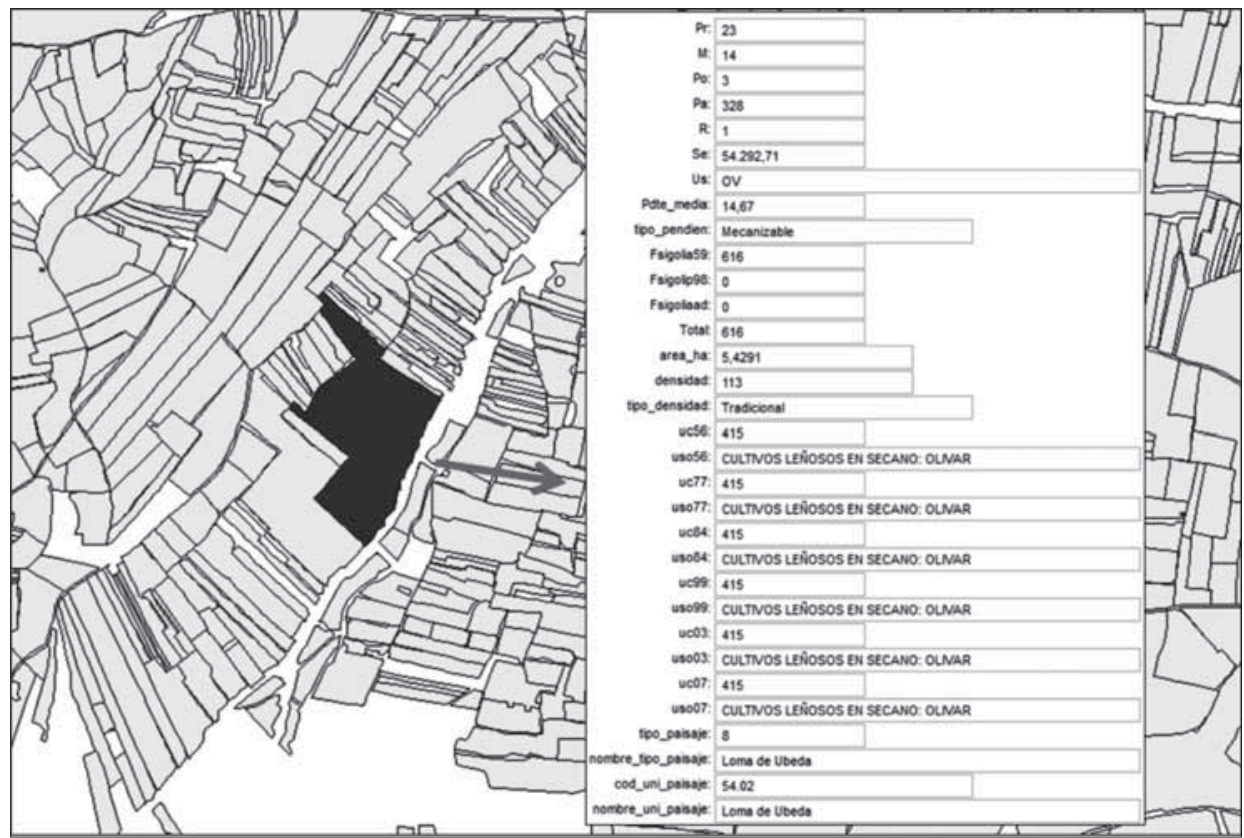

Fuente: SIGPAC 2008.

de la información, se decidió igualmente excluir del análisis todas aquellas parcelas cuyo número de olivos fuera igual o inferior a 10, pues entendíamos que en ningún caso tendrían la posibilidad de generar algún paisaje con valores intrínsecos determinantes y, por el contrario, pondría en riesgo la capacidad tanto del hardware como del software disponible para el manejo de la información parcelaria digital. Estamos hablando de más de 240.000 unidades de análisis, casi la quinta parte del total, pero que tan solo suponen el $1,43 \%$ de los olivos plantados y el 1,22\% de la superficie dedicada a este cultivo. En consecuencia, se ha trabajado efectivamente con casi 470.000 parcelas (tabla 2).

A cada una de estas parcelas se le ha asignado posteriormente un atributo temporal y espacial, a partir de las fuentes que se citan en el siguiente apartado. 
TABLA 2

CLASIFICACIÓN DE PARCELAS DE OLIVAR ACUERDO A LA INVESTIGACIÓN REALIZADA

\begin{tabular}{l|r|r|r}
\hline & Parcelas & \multicolumn{1}{|c|}{ Olivos } & \multicolumn{1}{|c}{ Sup. (ha) } \\
\hline Olivar considerado en el estudio (más de & $\begin{array}{r}469.044 \\
10 \text { olivos por parcela) }\end{array}$ & $\begin{array}{r}64.408 .807 \\
(37,65 \%)\end{array}$ & $\begin{array}{r}542.143,41 \\
(98,57 \%)\end{array}$ \\
\hline Olivar descartado en el estudio (menos de & 240.372 & 931.128 & $6.972,01$ \\
10 olivos por parcela) & $(19,29 \%)$ & $(1,43 \%)$ & $(1,22 \%)$ \\
\hline Complementarios a las parcelas olivareras & 536.400 & 0 & $21.058,59$ \\
(improductivo) & $(43,06 \%)$ & $(0 \%)$ & $(3,69 \%)$ \\
\hline Total & 1.245 .816 & 65.339 .935 & $570.174,01$ \\
\hline
\end{tabular}

Fuente: SIGPAC. 2008.

\section{Resultados}

Respecto a la pendiente, si bien cada parcela tiene su indicación precisa, hemos optado por presentar únicamente tres intervalos (figura 4), que vienen a coincidir con las parcelas donde a día de hoy (Colombo et al., 2015) es posible una total mecanización de las labores ( $<15 \%)$, aquellas en las que en estos momentos resulta imposible o claramente antieconómico (olivar de montaña con pendiente $>20 \%$ ) y una tercera en la que sería posible, mediante mejora tecnológica y asumiendo un mayor consumo de combustibles, la adaptación mecánica para reducir el trabajo manual al mínimo indispensable (15-20\%). Claramente, estas categorías representan posibilidades económicas contrastadas entre olivares que pueden competir razonablemente en el mercado (pendiente baja a estos efectos), aquellos para los cuales las ayudas resultan imprescindibles (pendiente moderada) y los que difícilmente pueden alcanzar un nivel de rentabilidad económica incluso con las ayudas que ahora contempla la PAC (pendiente elevada), tal y como ha quedado demostrado en trabajos previos (Consejo Económico y Social de la Provincia de Jaén, 2011).

Obviamente, la competitividad en los mercados no depende sólo de la pendiente y otras características físicas de las explotaciones olivareras, pero no por ello deja de ser tremendamente significativa. En términos estrictamente paisajísticos, no obstante, cabría limitarse al umbral del 20\% para diferenciar el olivar de montaña del que ocupa vegas y campiñas. En la figura 4 puede comprobarse, en efecto, la concentración de las pendientes mayores en el entorno de las serranías prebéticas y subbéticas que se despliegan por el sur y el este provincial, frente al dominio de las zonas de vega y campiña en el centro del espacio provincial, por donde discurre el Guadalquivir. 
FIGURA 4

\section{PENDIENTE MEDIA DE LAS PARCELAS OCUPADAS POR OLIVAR EN LA PROVINCIA DE JAÉN}

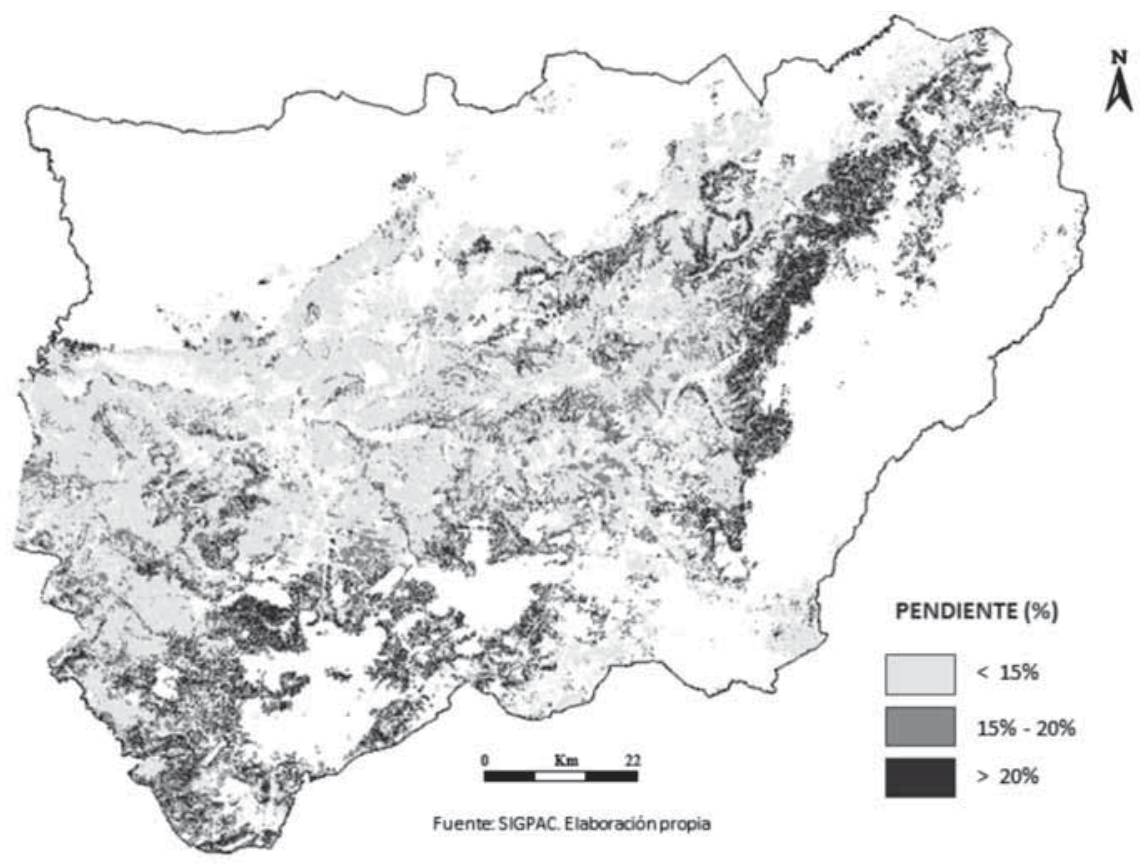

En buena lógica, la densidad de plantación se relaciona con la pendiente (figura 6), habida cuenta que la introducción de un mayor número de pies por superficie es propia de diseños adecuados al contexto productivista que supuso la aplicación de la PAC, cuya localización espacial preferente han sido las lomas, campiñas y vegas que hasta entonces se reservaban para los cereales, los cultivos industriales e incluso la hortofruticultura (Sánchez, Rodríguez y Gallego, 2015). Nuestro planteamiento, en este caso, ha sido establecer también tres intervalos: $<120,120-400$ y > 400 árboles/ha. Esto permitiría deslindar, a grandes rasgos, los denominados olivares tradicionales ${ }^{13}$, intensivos y superintensivos.

13 Como se hará notado, la expresión "olivar tradicional" es un comodín que se emplea con significados diferentes, como la edad de la plantación, la densidad de la misma (80100 olivos/ha) o sus resultados productivos y/o económicos. Esto genera confusión, cuando lo apropiado sería reservar el término para una connotación temporal antes que económica (bajos rendimientos), pues algunos olivares antiguos o de baja densidad de plantación están gestionados bajo principios técnicos modernos. 


\section{FIGURA 5}

\section{EJEMPLOS DE OLIVARES DE BAJA DENSIDAD DE PLANTACIÓN}
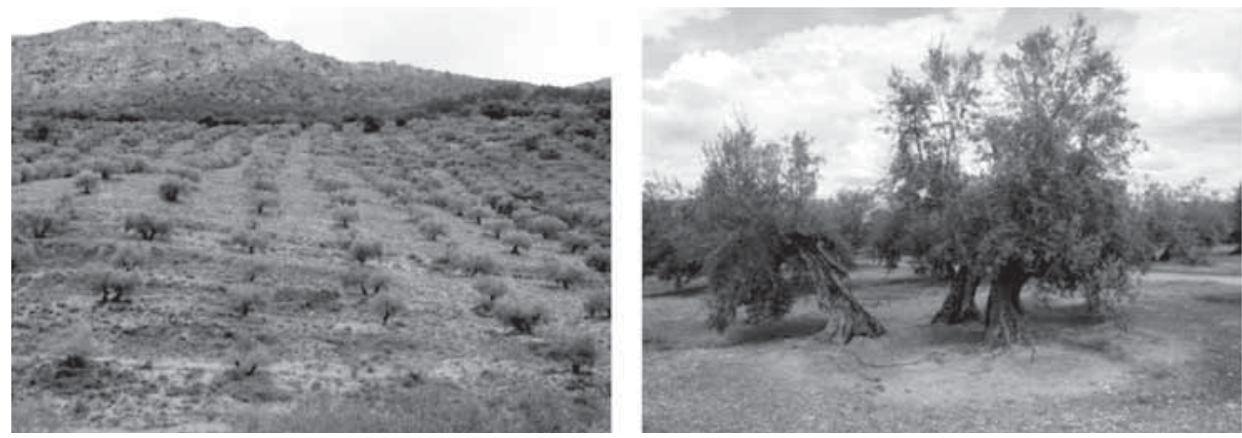

FIGURA 6

DENSIDAD DE PLANTACIÓN DE LAS PARCELAS OCUPADAS POR OLIVAR EN LA PROVINCIA DE JAÉN

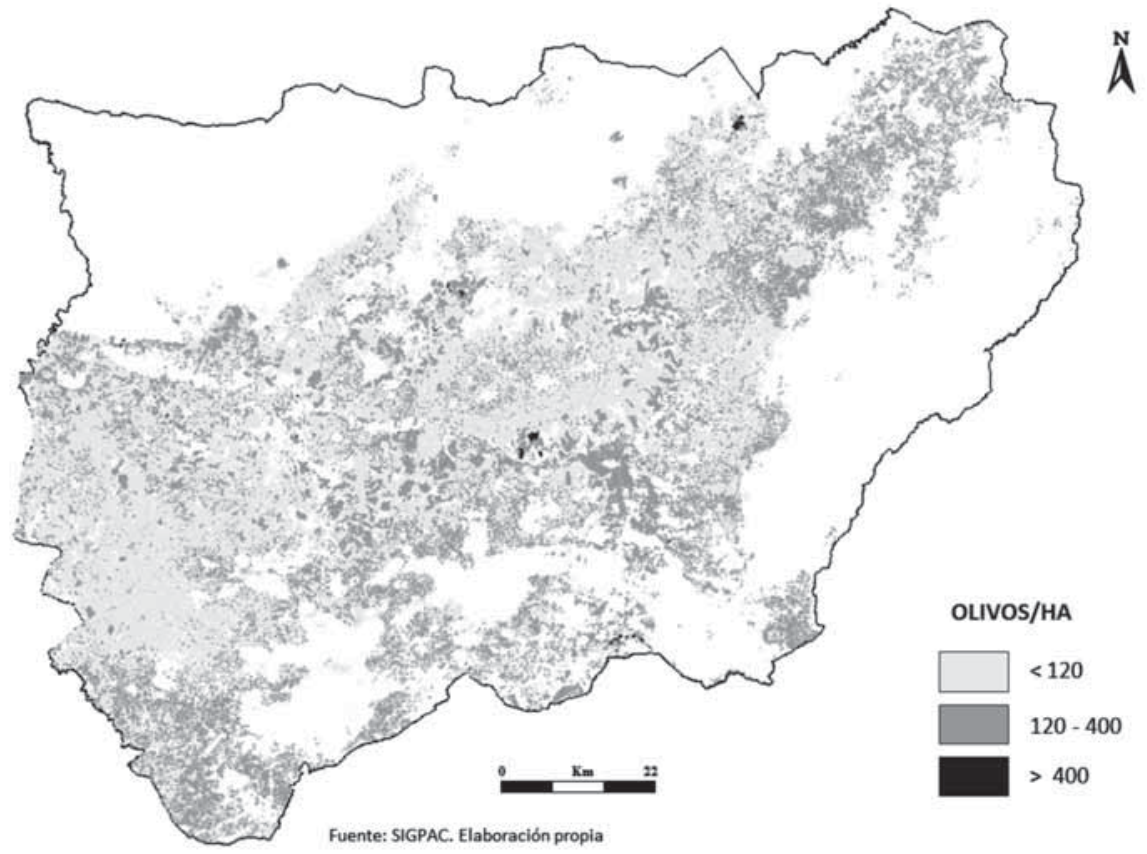

Estudios Geográficos, Vol. LXXVIII, 283, pp. 523-551, julio-diciembre 2017 ISSN: 0014-1496, eISSN: 1988-8546, doi: 10.3989/estgeogr.201718 
Como se puede ver, la última categoría está claramente infrarrepresentada, lo cual resulta lógico dado el desarrollo reciente de este tipo de explotaciones, que se han desarrollado mucho más en los nuevos países olivareros (Argentina o Australia son buenos ejemplos), mientras que en la región andaluza se concentran en las campiñas bajas del Guadalquivir, donde la dimensión económica y física de las explotaciones ha resultado más acorde con este nuevo planteamiento técnico necesitado de una gran capacidad financiera. A los efectos de resaltar aspectos paisajísticos, también cabría en este caso simplificar a dos grandes categorías, las correspondientes a baja y alta densidad.

La combinación de pendiente y densidad da como resultado la delimitación de 9 tipologías agrícolas ${ }^{14}$, tal y como se recoge en la tabla 3.

TABLA 3

SIGNIFICACIÓN DE LOS OLIVARES CONSIDERADOS EN EL ESTUDIO COMBINANDO DENSIDAD Y PENDIENTE

\begin{tabular}{l|r|r|r|r}
\hline & Parcelas $\left(\mathrm{n}^{0}\right)$ & \multicolumn{1}{|c|}{ Olivos $\left(\mathrm{n}^{0}\right)$} & \multicolumn{1}{c|}{ Sup. (ha) } & Sup. (\%) \\
\hline Baja densidad y pendiente elevada & 59.541 & 6.709 .135 & $67.979,09$ & 12,54 \\
\hline Baja densidad y pendiente moderada & 40.978 & 5.930 .965 & $62.942,26$ & 11,61 \\
\hline Baja densidad y pendiente baja & 135.828 & 20.315 .555 & $218.231,07$ & 40,25 \\
\hline Media densidad y pendiente elevada & 101.364 & 8.985 .760 & $59.780,97$ & 11,03 \\
\hline Media densidad y pendiente moderada & 34.012 & 4.728 .186 & $30.050,54$ & 5,54 \\
\hline Media densidad y pendiente baja & 96.624 & 16.754 .423 & $102.023,05$ & 18,82 \\
\hline Alta densidad y pendiente elevada & 173 & 16.110 & 33,47 & 0,01 \\
\hline Alta densidad y pendiente moderada & 78 & 48.827 & 114,40 & 0,02 \\
\hline Alta densidad y pendiente baja & 446 & 919.846 & 988,545 & 0,18 \\
\hline Total & 469.044 & 64.408 .807 & $542.143,41$ & 100,00 \\
\hline
\end{tabular}

Fuente: SIGPAC. 2008.

Los siguientes pasos se relacionan con la caracterización temporal y espacial-paisajística de cada parcela. En ese sentido, manejando la información que ofrece la Red de Información Ambiental de Andalucía (REDIAM) de la Consejería de Medio Ambiente de la Junta de Andalucía bajo el epígrafe de Usos

\footnotetext{
14 Algunos ejemplos de estos tipos se presentan en las figuras 5 y 8 .
} 
y Coberturas del suelo de Andalucía, hemos adquirido sus atributos temporales a partir de la superposición espacial de las parcelas con los usos del suelo de cada una de las coberturas pudiendo establecer, mediante este proceso de captura de información, tres cortes cronológicos en relación a la aparición de los olivares jiennenses, que se corresponden con el período anterior a 1957, el comprendido entre este año y 1984, y el que va desde entonces a 2007 (figura 7).

\section{FIGURA 7}

EDAD DE LA PLANTACIÓN DEL OLIVAR EN LA PROVINCIA DE JAÉN

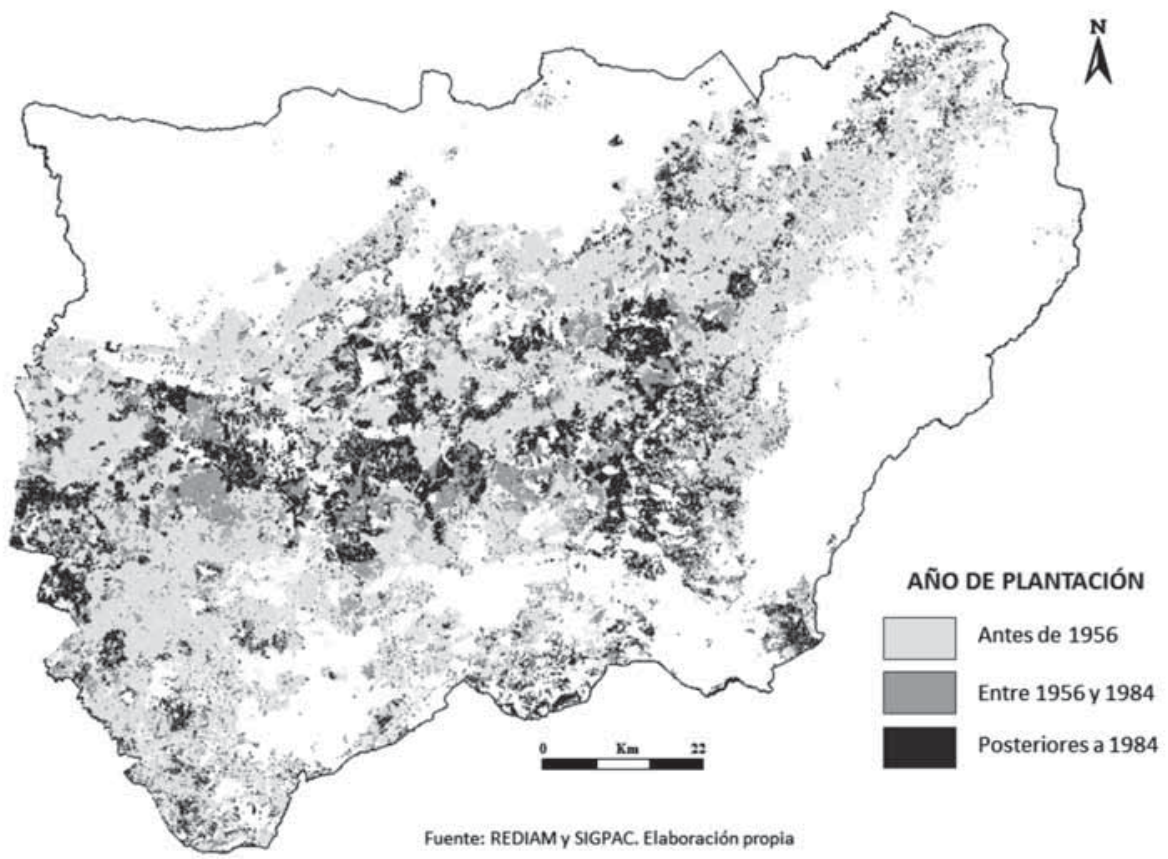

Más allá de que estos cortes estén condicionados por la disponibilidad de las fuentes ${ }^{15}$, lo cierto es que pueden representar de una manera más o menos

15 Nos hubiera gustado, en este sentido, emplear como año de referencia a 1986 pero la información sobre usos de ese año no esta digitalizada, aunque sí disponible en términos estadísticos y cartográficos en el Mapa de cultivos y aprovechamientos de la provincia (Ministerio de Agricultura, 1987). 
fidedigna la existencia de tres períodos históricos completamente diferenciables, que se corresponden con contextos de diferente intensidad en términos de revolución verde (Silva Pérez, 2009). Así, si el primero puede identificarse con la agricultura pre-productivista y productivista inicial (tradicionales); el segundo cabe caracterizarlo como de transición a un productivismo pleno, que es el que se consolida definitivamente a partir de las orientaciones de la PAC a partir de mediados de los años ochenta, cuya mejor expresión es la aparición de los olivares productivistas (intensivos y superintensivos), donde el regadío ha alcanzado un gran protagonismo.

FIGURA 8

EJEMPLOS DE OLIVARES DE ALTA Y MEDIA DENSIDAD DE PLANTACIÓN
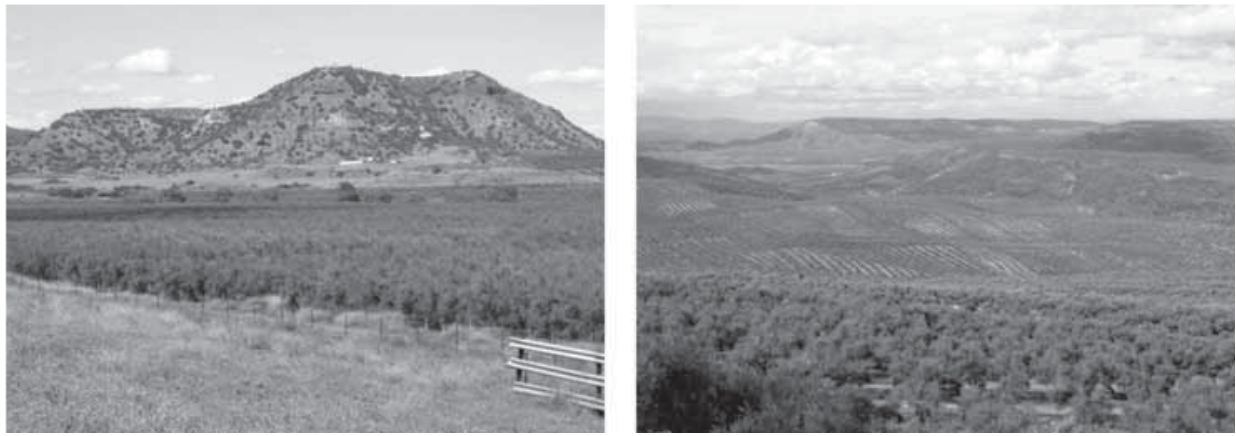

Los atributos espaciales, por su parte, se han basado en una interpretación del Atlas de los Paisajes de España (Mata y Sanz, 2003), reagrupando las 26 unidades de paisaje reconocidas en la provincia de Jaén en nueve zonas de homogeneidad a escala comarcal o subcomarcal (tipos de paisaje), donde es dominante la geomorfología como elemento de reconocimiento.

Una plasmación completa de la base de la información manejada es la que se recoge en la tabla 4. En ella se observa que, a pesar de que se ha planteado nuestro trabajo sobre un único uso del suelo y circunscrito a la provincia de Jaén, el máximo teórico de combinaciones de las variables seleccionadas (pendiente, densidad y edad de la plantación) nos podría llevar a considerar un número extraordinariamente elevado de clases y tipos de paisajes olivareros. 
TABLA 4

DISTRIBUCIÓN DEL OLIVAR EN TIPOS Y UNIDADES DE PAISAJE GEOGRÁFICO

\begin{tabular}{|c|c|c|c|c|}
\hline Tipo de paisaje & Unidad de paisaje & Parcelas & Olivos & Sup. (ha) \\
\hline \multirow{4}{*}{$\begin{array}{l}\text { Macizos y sierras } \\
\text { subbéticas }\end{array}$} & Montes de Granada & 1.727 & 257.629 & $2.189,77$ \\
\hline & Sierras de Jaén y Martos & 30.662 & 2.735 .522 & $24.168,33$ \\
\hline & Sierras de Valdepeñas de Jaén y Campillo de Arenas & 19.943 & 1.837 .706 & $14.180,89$ \\
\hline & Sierra Magina & 27.446 & 2.488 .459 & $18.793,19$ \\
\hline \multirow{5}{*}{ Macizos prebéticos } & Sierra del Pozo & 1.270 & 133.933 & $1.116,97$ \\
\hline & Sierra de Cazorla y Las Villas & 16.326 & 1.795 .817 & $15.056,46$ \\
\hline & Sierra de Segura & 8.405 & 830.232 & $6.234,04$ \\
\hline & Sierras de Alcaraz y Beas de Segura & 26.963 & 2.443 .061 & $18.067,15$ \\
\hline & Calar del Río Mundo & 3.235 & 245.678 & $1.743,47$ \\
\hline \multirow{4}{*}{$\begin{array}{l}\text { Sierras, valles y } \\
\text { penillanuras de Sierra } \\
\text { Morena }\end{array}$} & Sierras entre los ríos Jándula y Guadalimar & 1.594 & 215.720 & $2.077,87$ \\
\hline & Sierra Morena Oriental & 4.047 & 663.101 & $5.734,27$ \\
\hline & Sierras y Valles de Montoro y Adamuz & 1.040 & 269.807 & $2.278,70$ \\
\hline & Penillanura incidida del Jándula & 340 & 106.567 & 841,96 \\
\hline \multirow{4}{*}{$\begin{array}{l}\text { Hoyas y depresiones } \\
\text { béticas }\end{array}$} & Campiña de Alcaudete & 20.678 & 2.342 .521 & $17.049,32$ \\
\hline & Depresión de Alcalá la Real & 20.938 & 2.563 .400 & $25.115,69$ \\
\hline & Campiña de Guadahortuna & 1.175 & 823.727 & $4.549,32$ \\
\hline & Hoya de Baza & 4.925 & 534.349 & $3.625,63$ \\
\hline \multirow{2}{*}{$\begin{array}{l}\text { Pasillos } \\
\text { intramontanos béticos }\end{array}$} & Valle del Guadiana Menor & 7.149 & 1.195 .544 & $7.202,68$ \\
\hline & Pasillo de Alcaraz-Puente Génave & 6.672 & 1130.191 & $8.038,45$ \\
\hline \multirow{3}{*}{$\begin{array}{l}\text { Campiñas al norte del } \\
\text { Guadalquivir }\end{array}$} & La Loma de Chiclana & 30.085 & 4.133 .551 & $37.075,21$ \\
\hline & Campiña de Vilches & 9.885 & 2.041 .999 & $16.657,07$ \\
\hline & Campiña de Bailen & 21.880 & 4.012 .332 & $35.047,69$ \\
\hline \multirow{2}{*}{$\begin{array}{l}\text { Campiñas al sur del } \\
\text { Guadalquivir }\end{array}$} & Campiñas al oeste de las Sierras de Cazorla y Segura & 49.848 & 10.034 .926 & $77.144,07$ \\
\hline & Campiña al sur del Guadalquivir & 74.380 & 12.065 .392 & $114.367,95$ \\
\hline Loma de Úbeda & Loma de Úbeda & 71.609 & 8.181 .825 & $72.926,69$ \\
\hline Vega del Guadalquivir & Vega del Guadalquivir entre Villa del Río y Mengíbar & 6.782 & 1.323 .035 & $10.838,42$ \\
\hline \multirow[t]{2}{*}{ Sin determinar } & Sin determinar & 40 & 2.783 & 19,16 \\
\hline & Total & 469.044 & 64.408 .807 & $542.143,41$ \\
\hline
\end{tabular}

En la figura 9 se agrupan las parcelas de olivar según el tipo de paisaje en el que se localizan. 
FIGURA 9

EL OLIVAR EN LOS DIFERENTES TIPOS DE PAISAJE GEOGRÁFICO

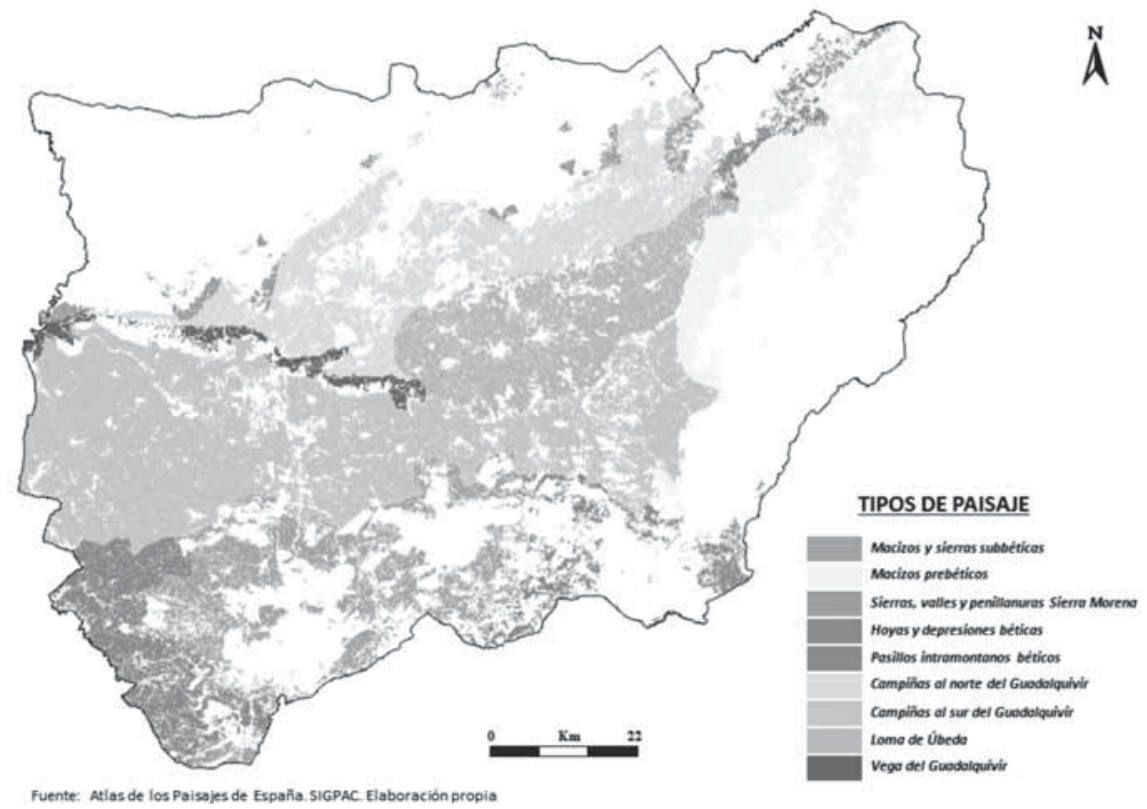

\section{Conclusiones}

Hasta el momento hemos perseguido el objetivo de mostrar la diversidad del olivar; presentando tal realidad como el resultado de dinámicas temporales y tipologías agrarias que se manifiestan en contrastadas localizaciones paisajísticas. Otra cosa son, sin embargo, los paisajes olivareros. De entrada, aunque seguimos aún muy pegados al uso del suelo, parece evidente que los grandes modelos económico-territoriales a los que nos hemos referido deben conformar paisajes reconocibles. En ese sentido, creemos estar en condiciones de proponer una primera aproximación a los paisajes del olivar, para lo que en algún caso haremos entrar en juego nuevas variables que están integradas en la base de datos que hemos creado. En particular, podemos considerar las siguientes grandes categorías (véanse figuras 10 y 11 ):

- Olivares marginales: son aquellos que están plantados sobre tierras que tienen tal consideración de acuerdo al mapa de capacidad de uso del 
suelo (figura $\mathrm{n}^{\circ}$ 1). En principio se trata de una superficie de 153.657 ha. Esta cifra es considerablemente mayor que la reconocida en estudios anteriores, de forma que es comprensible que pueda definirse una subcategoría de olivares manifiestamente marginales desde una perspectiva ecológica y económica (Guzmán Álvarez, 2004), lo que podría servir para recomendar su gestión bajo principios estrictamente ambientales o, lo que es lo mismo, favorecer que se devuelva al suelo su verdadera vocación forestal de una manera ordenada (Guzmán y Navarro, 2005).

- Olivares en áreas protegidas: son aquellos que se encuentran en el interior de áreas protegidas, de manera que cuentan ya con un reconocimiento explícito. Esto no necesariamente implica una consideración favorable en los documentos normativos que ordenan territorialmente estos territorios. Es más, dada la orientación ambientalista de estos no dejan de aparecer referencias a los efectos más negativos que en algunos casos suponen, con llamamientos específicos a evitar las elevadas tasas de erosión que ahora se reconocen y, en ocasiones, a la conveniencia de facilitar la conversión del uso agrícola a forestal. Pero, en sentido contrario, en la intención de vincular conservación y desarrollo, los olivares de estas zonas son también contemplados como una oportunidad (Sánchez y Gallego, 2016). En definitiva, una parte de estos olivares podría entrar en la categoría de marginalidad a la que antes nos hemos referido, pero en otros casos se puede asegurar su funcionalidad económica y ambiental de acuerdo a las prescripciones incluidas en los respectivos planes de ordenación de los recursos naturales y las que resultan del cumplimiento de la condicionalidad para el cobro de ayudas de la PAC o por el acogimiento a programas agroambientales (producción ecológica o integrada). De acuerdo con la superposición que hemos realizado entre el SIGPAC y el territorio de los Lugares de Interés Comunitario reconocidos en la provincia, en conjunto son unos unas $26.000 \mathrm{ha}$. Por otra parte, esta categoría debería ampliarse con la delimitación de olivares de especial interés. Nos referimos a casuísticas tales como las que se refieren a olivares sitos en el interior de ámbitos amparados bajo alguna Denominación de Origen Protegido. Desde luego, no basta con considerar el ámbito territorial de las mismas, pues se refieren a municipios completos que si, en términos generales, tienen una superficie considerable en zonas de montaña, incluyen también otras con características que no implican limitaciones productivas. Un criterio altimétrico, en este caso, podría servir para deslindar ambas situaciones. Lo que está claro, no obstante, 
es que se trata en muchas ocasiones de olivares colindantes con las áreas protegidas a las que antes nos referíamos. Por lo demás, compartimos la hipótesis de la existencia de una relación fuerte entre calidad del producto agrario (el aceite en este caso), el terreno donde se produce y el paisaje (en su dimensión cultural y patrimonial) en que se traduce (Andrieu, Alexandre y Godron, 2014).

FIGURA 10

APROXIMACIÓN CARTOGRÁFICA A LOS PAISAJES DE OLIVAR EN LA PROVINCIA DE JAÉN

Olivares en suelos con capacidad marginal Olivares en el interior de áreas protegidas


FIgURA 11

EJEMPLOS DE LA DIVERSIDAD PAISAJÍSTICA DEL OLIVAR

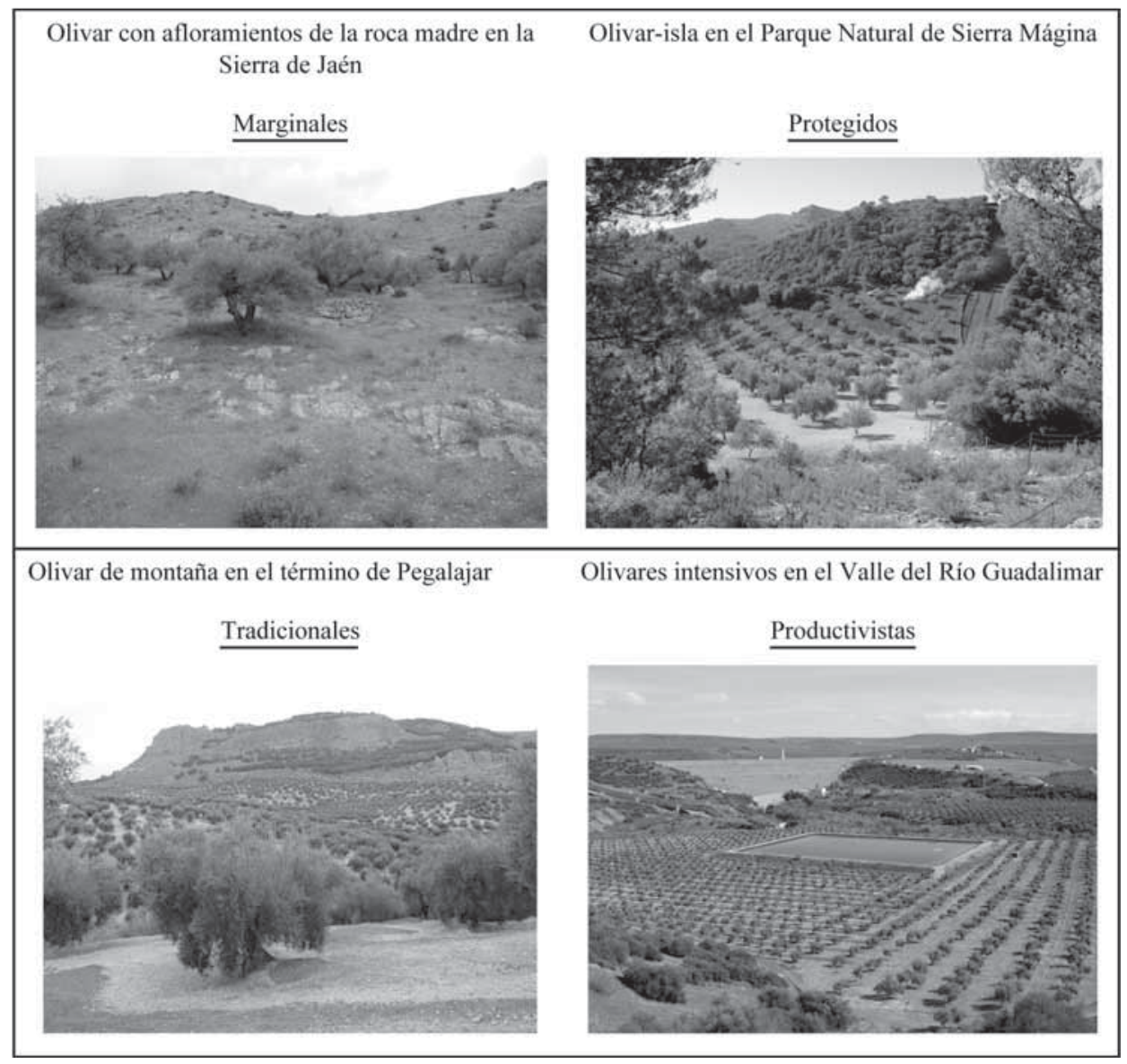

Fotos José D. Sánchez Martínez

- Olivares tradicionales: empleamos este término para referirnos a los surgidos antes de 1984 siempre que ocupen terrenos con cierta dificultad productiva, esto es, que no puedan participar del productivismo pleno y mantengan como identidad la densidad de plantación inicial, en este caso por debajo del umbral de de 120 olivos/ha. Es esta categoría, el umbral de 800 metros sirve para deslindar los olivares de montaña, mientras el de más del $20 \%$ nos permite reconocer los olivares en pendiente, que 
por cierto están muy presentes en altitudes inferiores a la mencionada. Una parte de estos olivares tradicionales, surgidos en muchos casos de la necesidad de encontrar vías de supervivencia en un territorio hostil y convertidos en símbolo del ansia de las clases populares por acceder a la propiedad agraria, se hallan en una situación de dificultad que, en no pocas ocasiones, los enfrenta al abandono temporal o definitivo. Y entre ellos se pueden reconocer algunos elementos de posible reconocimiento patrimonial posterior, como puedan ser los restos de cultivos en mosaico, combinación promiscua con otros leñosos o islas de olivar entre masas de vegetación forestal; en algunos casos aparecen también cultivos aterrazados en los que se mantienen muretes de piedra seca.

- Olivares productivistas y neoproductivistas: nos referimos a los olivares surgidos de la PAC o plenamente adaptados a sus requerimientos de intensificación. Son todos los que no se han contemplado en las tres categorías anteriores. En este sentido, el elemento de diferenciación principal, además del momento de aparición, es la disponibilidad de riego y una pendiente moderada. En el caso de los neoproductivistas, por su parte, es la densificación de la planta lo que mejor denota el novísimo paisaje que muestran. En todo caso, en la figura 8 no se ha diferenciado este extremo.

\section{REFLEXIÓN FINAL}

Una de las mayores oportunidades que puede brindar la elaboración de un expediente para solicitar la inclusión del olivar andaluz en la Lista del Patrimonio Mundial es, en nuestra opinión, la de poner una vez más sobre la mesa la discusión filosófica sobre el modelo de olivar que se quiere y pueda resultar más conveniente en términos de sostenibilidad. En concreto, puede ser una ocasión para enderezar una situación claramente contradictoria, que consiste en ensalzar los valores gastronómicos y salutíferos del aceite de oliva, como parte integrante fundamental de la dieta mediterránea, al mismo tiempo que no se atajan los graves problemas ambientales que arrastra el sistema productivo (Scheidel y Krausmann, 2011). Es una oportunidad, en suma, para tratar de acercar el deseo de un olivar biodiverso, sostenible y resiliente (idealizado en el discurso político y mediático con expresiones como «bosque de olivar») a una realidad que, hoy por hoy, está más próxima a la de un "desierto de olivar». Es una precondición, en realidad, para poder reivindicar el papel del paisaje y el patrimonio agrario como activo de 
desarrollo territorial, tal y como se preconiza en el Plan Director del Olivar de Andalucía.

Obviamente, la multiplicidad de opciones agronómicas existentes impide que este proceso pueda ser general y acelerado. Pero es el momento de poner como objetivo prioritario la reestructuración ecológica del olivar, pues sin este requisito difícilmente se podría aspirar a tener un reconocimiento que se adquiere por la demostración de valores universales excepcionales que puedan servir de modelo, ejemplo o inspiración. Es en los territorios productores más vulnerables (olivares tradicionales de montaña), donde se encuentran probablemente los mejores ejemplos de olivares de interés patrimonial, donde deberían apoyarse especialmente los procesos interrelacionados de ecologización-diferenciación del producto-patrimonialización-oleoturismo. Y todo ello, porque aquí si puede alcanzar el olivar la categoría de bosque aclarado hasta alcanzar una posición de madurez ecológica intermedia gracias a una estructura paisajística con discontinuidades de vegetación espontánea (Pajarón Sotomayor, 2008).

\section{Agradecimientos}

Este trabajo se enmarca en el Proyecto de Investigación de Excelencia «Caracterización y perspectivas del monocultivo olivarero jiennense: conformación espacio-temporal, diversidad paisajístico-agronómica y dinámicas territoriales inmediatas», financiado por la Consejería de Economía, Innovación y Ciencia de la Junta de Andalucía (SEJ - 1153, convocatoria 2012).

\section{BiBLIOGRAFÍA}

Armesto López, X. (2005): "Notas teóricas en torno al concepto de postproductivismo agrario". Investigaciones Geográficas, 36, pp.: 137-156.

Asociación Española de Municipios del Olivo (2010): Aproximación a los costes del cultivo del olivo. Cuaderno de conclusiones del seminario AEMO. http://www.aemo.es/ get.php?pathext=descargas/Costes_AEMO.pdf (acceso 10/06/2011)

Araque Jiménez, E. (2015): Análisis del impacto socioeconómico de las declaraciones de los Parques Naturales en la provincia de Jaén. Jaén, Consejo Económico y Social de la provincia de Jaén.

Beaufoy, G. (2001): The environmental impact of olive oil production in the European Union: practical options for improving the environmental impact.http://ec.europa.eu/ environment/agriculture/pdf/oliveoil.pdf (acceso de 15/12/2007) 
Belletti, G.; Marescotti, A., Sanz-Cañada, J. y Vakourafis, H. (2015): "Linking protection of geographical indications to the environment: evidence from the European Union olive-oil sector". Land Use and Planning, 48: pp. 94-106.

Cañizares Ruiz, M. C. y Ruiz Pulpón, A. R. (2014): "El viñedo en Castilla-La Mancha: el reconocimiento de un paisaje cultural". En Pavón Gamero, D. et al. (eds.): XVII Coloquio de Geografía Rural. Revalorizando el espacio rural: leer el pasado para ganar el futuro. Girona, Documenta Universitaria, pp. 305-316.

Castillo Ruiz, J. y Martínez Yánez, C. (2014): "El patrimonio agrario: definición, caracterización y representatividad en el ámbito de la UNESCO". Boletín de la Asociación de Geógrafos Españoles, 66, pp. 105-124.

Colombo, S.; Perujo, M. y Ruz, A. (2015): "El olivar tradicional jiennense frente a la reforma de la PAC". En VV. AA.: El Aceite de Oliva. Actas Simposio Expoliva 2015. Jaén, Fundación del Olivar. Disponible en CD-ROM.

Consejería de Agricultura, Pesca y Desarrollo Rural (2015): Decreto 103/2015, de 10 de marzo, por el que se aprueba el Plan Director del Olivar. Boletín Oficial de la Junta de Andalucía, 54, pp. 8-154.

Consejo Económico y Social de la Provincia de Jaén (2011): Análisis de la rentabilidad económica de las explotaciones de olivar en la provincia de Jaén. http://www.dipujaen. es/export/sites/default/galerias/galeriaDescargas/diputacion/dipujaen/CES/otrasimagenes/DICTAMEN_DEL_CES_2010documento_finall.pdf (acceso 13/06/2011)

European Union Environmental Directorate-General (2010): LIFE among the olives. Good Practice in Improving Environmental Performance in the Olive Oil Sector.

http://ec.europa.eu/environment/life/publications/lifepublications/lifefocus/ documents/oliveoil_en.pdf (acceso de 09/07/2015)

Foray, D. (2013): "Fundamentos económicos de la especialización inteligente". Ekonomiaz, 83 (2), pp.. 55-81.

Gómez-Limón Rodríguez, J. A. y Arriaza Balmón, M. (2011): Evaluación de la sostenibilidad de las explotaciones de olivar en Andalucía. Málaga, Analistas Económicos de Andalucía.

Guzmán Álvarez, J. R. (2004): Geografía de los paisajes del olivar andaluz. Sevilla, Consejería de Agricultura y Pesca de la Junta de Andalucía.

Guzmán Álvarez, J. R. (2007): "El Palimpsesto cultivado. Propuesta de un catálogo de paisajes culturales históricos del olivar andaluz". I Congreso de la Cultura del Olivo. Jaén, Instituto de Estudios Giennenses, pp. 673-694.

Guzmán Álvarez, J. R. y Navarro Carrillo, R. M. (2005): "Restauración ecológica de olivares marginales: potencialidades y limitaciones". Ecosistemas: Revista científica y técnica de ecología y medio ambiente, 14 (2), pp. 116-131.

Guzmán Álvarez, J. R. y Zoido Naranjo, F. (2013): "El olivar andaluz en su dimensión paisajística. Espacio vivido y paisaje sentido". En VV. AA.: Andalucía. El olivar. Sevilla, Grupo de Estudios Avanzados sobre Territorio y Medio Ambiente, pp. 63-81.

Ilbery, B. y Bowler, I. (1998): "From agricultural productivism to postproductivism". En Ilbery, B. (ed.): The geography of rural change. London, Longman, pp. 57-84. 
Junta de Andalucía (2005): Mapa de los paisajes de Andalucía. Escala 1:100.000.http:// www.juntadeandalucia.es/medioambiente/site/portalweb (acceso 10/12/15)

Junta de Andalucía (2008): El sector del aceite de oliva y de la aceituna de mesa en Andalucía. Sevilla, Junta de Andalucía. Consejería de Agricultura y Pesca.http:// www.juntadeandalucia.es/agriculturaypesca/portal/servicios/estadisticas/estudiose-informes/agricultura/olivar/sector-aceite-aceituna-mesa-andalucia.html (acceso 13/06/2011).

Junta de Andalucía (2011): Estrategia del paisaje de Andalucía. Sevilla, Consejería de Medio Ambiente.

Junta de Andalucía (2014): Programa de desarrollo rural de Andalucía. http://www. juntadeandalucia.es/export/drupaljda/PDRA14-20v4.pdf (acceso de 15/06/2915)

Mata Olmo, R. (1997): "Sistemas y paisajes agrarios españoles". En Gómez Benito, C. y González Rodríguez, J. J.: Agricultura y Sociedad en la España Contemporánea. Madrid, Ministerio de Agricultura, Pesca y Alimentación y Centro de Investigaciones Sociológicas, pp. 109-172.

Mata Olmo, R. (2001): "Los paisajes agrarios". En Gil Olcina, A. y Gómez Mendoza, J. (coords.): Geografía de España. Barcelona, Editorial Ariel, pp. 299-325.

Mata Olmo, R. y Sanz Herraiz, C. (2003): Atlas de los paisajes de España. Madrid, Ministerio de Medio Ambiente.

Ministerio de Agricultura, Pesca y Alimentación (1987): Mapa de cultivos y aprovechamientos de la provincia de Jaén. Escala 1:200.000. Madrid, Publicaciones del MAPA.

Maya Frades, A. e Hidalgo González, C. (2009): "Nuevas funciones y desarrollos de los territorios rurales europeos: su necesaria adaptación a método de producción duraderos y sostenibles. Boletín de la Asociación de Geógrafos Españoles, 490, pp. 255-279.

Medina Rosillo, T. J. (2015): Los premios a la calidad, término de una evolución histórica, instituciónal, agronómica, industrial y económica del aceite de oliva. Trabajo Fin de Máster en Economía y Desarrollo Territorial. Universidad de Jaén. Original mecanografiado.

Molinero, F. (2013, coord.): Atlas de los paisajes agrarios de España. Tomo I. Las clases de paisajes agrarios de España. Las unidades de paisajes agrio de la España atlántica. Madrid, Ministerio de Agricultura, Alimentación y Medio Ambiente.

Molinero, F. (2014, coord.): Atlas de los paisajes agrarios de España. Tomo II. Las unidades de paisaje agrario de la España mediterránea. Madrid, Ministerio de Agricultura, Alimentación y Medio Ambiente.

Molinero, F; Alario, M. y Baraja, E. (2015): "Una clasificación de los paisajes agrarios basada en las ocupaciones del suelo". En De la Riva, J. et al. (eds.): Análisis espacial y representación geográfica: innovación y aplicación. Zaragoza, Universidad de Zaragoza y Asociación de Geógrafos Españoles, pp. 1123-1132.

Molinero, F; Tort, J. y Ojeda, J. F. (2010, eds.): Los paisajes agrarios de España. Caracterización, evolución y tipificación. Madrid, Ministerio de Medio Ambiente, 
Rural y Marino.

Moya García, E.; Cuesta Aguilar, M. J. y Sánchez Martínez, J. D. (2015): "Los apuntes topográficos del Instituto Geográfico y Estadístico como fuente para el estudio del paisaje agrario: el ejemplo del olivar en la provincia de Jaén". En De la Riva, J. et al. (eds.): Análisis espacial y representación geográfica: innovación y aplicación. Zaragoza, Universidad de Zaragoza y Asociación de Geógrafos Españoles, pp. 1143-1152.

Organización para la Cooperación y el Desarrollo Económico (2006): El nuevo paradigma rural. Políticas y gobernanza. París, OCDE.

Paniza Cabrera, A.; García Martínez, P. y Sánchez Martínez, J. D. (2015): Análisis de la expansión del olivar en la provincia de Jaén a través de fuentes cartográficas (19562007). Anales de Geografía de la Universidad Complutense, 35(1), pp. 119-137.

Pajarón Sotomayor, M. (2008): "El olivar como agrosistema". En Gracia Navarro, S. y Pacheco Reyes, R.: Tecnología y desarrollo sostenible en el olivar. Baeza, Instituto de la Ingeniería de España, pp. 23-33.

Peris-Ortiz, M. et al. (2016, eds.): Wine and Tourism. A Strategic Segment for Sustainable Economic Development. Londres. Springer.

Rodríguez Cohard, J. C.; Sánchez Martínez, J. D. y Gallego Simón, V. J. (2015): "La producción de aceites de alta gama como estrategia de desarrollo local: alcance y limitaciones en la provincia de Jaén". En VV. AA.: El aceite de oliva. Actas Simposio Científico-Técnico Expoliva 2015. Jaén, Fundación del Olivar. Disponible en formato digital.

Ruiz Flaño, P. y Lasanta Martínez, T. (2014): "Los territorios del viñedo de Rioja: el paisaje como recurso". En Molinero, F. (coord.): Atlas de los paisajes agrarios de España. Madrid, Ministerio de Agricultura, Alimentación y Medio Ambiente, pp. 697-708.

Sánchez Martínez, J. D. y Galiano Parras, S. (2014): “La expansión contemporánea del olivar en la provincia de Jaén: dinámica espacio-temporal de un monocultivo excepcional". En Castro, E. (ed.): Proyectos de Investigación 2011-12. Jaén, Publicaciones de la Universidad de Jaén, pp. 111-165.

Sánchez Martínez, J. D. y Gallego Simón, V. J. (2010): "Las campiñas olivareras andaluzas: La Loma de Úbeda". En Molinero, F., Ojeda, J. F. y Tort, J. (eds.): Los paisajes agrarios de España. Caracterización, evolución y tipificación. Madrid, Ministerio de Medio Ambiente, Medio Rural y Marino, pp. 317-335.

Sánchez Martínez, J. D. y Gallego Simón, V. J. (2016): "El cultivo de olivar en áreas protegidas de Andalucía: localización, ordenación territorial, conflictos y oportunidades". En Madureira, L. et al. (eds.): Smart and Inclusive Development in Rural Areas. Book of proceedings of the 11th Iberian Conference on Rural Studies. Vila Real: Universidade de Tras-os-Montes e Alto Douro, pp. 763-768.

Sánchez Martínez, J. D. y Paniza Cabrera, A. (2015): "The Olive Monoculture in the South of Spain". European Journal of Geograph, 6(3), pp. 16-29.http://www. eurogeographyjournal.eu/articles/EJG020603CABRERA.pdf (acceso de 11/03/2015) 
Sánchez Martínez, J. D.; Rodríguez Cohard, J. C. y Gallego Simón, V. J. (2015): "La PAC 2015-2020 y su influencia en los territorios andaluces de especialización oleícola". Comunicación presentada al XXXI ENCUENTRO ARETHUSE ¿Qué une y qué separa a Europa? Políticas comunes en la Unión Europea y su impacto en los países, la empresa y la sociedad. http://www.pe.uma.es/arethuse/ (acceso de 15/11/2015).

Scheidel, A. y Krausmann, F. (2011): "Diet, trade and land use: a socio-ecological analysis of the transformation of the olive oil system". Land Use Policy, 28, pp. 47-56.

Silva Pérez, R. (2009): "Agricultura, paisaje y patrimonio territorial. Los paisajes de la agricultura vistos como patrimonio". Boletín de la Asociación de Geógrafos Españoles, 49, pp. 309-334.

Van der Ploeg, J. D. y Roep, D. (2003): "Multifunctionalty and rural develpment: the actual situation in Europe". En Van Huylenbroeck, G. y Durand, G. (eds.): Multifunctional Agriculture: A new paradigm for European Agricultura and Rural Development. Hampshire, Asghate, pp. 37-53.

Fecha de recepción: 7 de abril de 2016.

Fecha de aceptación: 30 de marzo de 2017. 